\title{
Leadership for Social Justice as an Antidote to Social Pathogenesis
}

\section{Evangelia Papaloi}

$\mathrm{PhD}$, Tutor at the Hellenic Open University (Management of Educational Institutions), Greece

\begin{abstract}
The main objective of this paper is to offer a discussion framework and arguments about how educational leaders can administer dynamic and sustainable educational organizations under the new circumstances of modern societies emphasizing on managing students' social exclusion (at micro and macro-level), giving all actors involved the tools and skills to think universally and critically and, thus, structuring the individuality of the modern citizen.

It is important to note that, nowadays, organizations have to play a larger and more positive role in society by putting the emphasis both on the socio-emotional and cognitive development of its members and the significance of their mission. Furthermore, it is obvious that, organizations continually redesign their interfaces as they decide which activities they will undertake and which activities will be purchased or conducted out.

Thus, the overall goal of this paper is to depict a new type of school leader who will not only have an active role in the daily operation and management of his educational community but, will have a transformative role in shaping organizational culture and ethics as well as organization's reputation and character with a view to contributing to social prosperity by fostering citizenship and social inclusion.
\end{abstract}

Keywords: leadership for social justice, organizational culture, democratic practices, awareness, social inclusion.

JEL Classification: D63, Z1.

(C) The Author, 2017. This article is published with open access at ARMG Publishing.

\section{Educational organizations and social pathogenesis}

Organizations occupy a central role in our lives, enabling us to be more efficient, to access goods and services, and to share information and experiences across the globe. Worldwide, there are many paradigms where organizations with a view to become more competitive, neglect that their strongest point is their human capital, and, often experience lower productivity, lower employee morale, low efficiency and negative working climate. Despite the rhetoric for enhancing organizational meaningfulness and organization's character so as to contribute to social prosperity, little effort has been made towards this direction.

To start with, as far as educational organizations are concerned, we have to admit that nowadays, in many educational organizations, there exist serious shortcomings regarding the adequacy and effectiveness of mechanisms which assure the substantial achievement of their goals and mission. Moreover, evidence suggests that, educational organizations seem to passively respond to society's needs, by transferring knowledge which does not lead to students' full development and, by maintaining and reproducing social inequalities (Biesta, 2009; Chomsky, 1987; Kyritsis, 2016).

More specifically, educational organizations as institutions are an integral part of social reality and are composed of many elements that interact with each other creating an environment which is characterized by complexity. Their fundamental aim is, through education, learning and socialization, to transfer cognitive and cultural knowledge and skills among young people so that they will be able to cope with the roles they adopt as active citizens and as professionals.

Over the past decades, both policy makers and practitioners have united their voice and consider education as leverage for "producing" good citizens. Consequently, discussions regarding just practices at school and the development of citizenship education have flourished, fostering school's inter-connection with society's needs and demands and giving emphasis on the ways in which democratic values are learned through curricula and everyday practices (Hwa, 2008). 
Undoubtedly, educational organization should be a considerable leverage for development of its members as well as for social prosperity, by promoting the principles of justice, freedom, equality, cooperation, mutual aid, unity and harmonious coexistence of all members of our society; by encouraging the development of a collective consciousness; and, by developing its members' cognitive, emotional, social skills so as to actively participate at society's needs.

Nevertheless, schools systematically frustrate the full personal development; legitimizing rather than alleviating social inequality (...), young people are taught behavioral characteristics which mainly include the submission and yieldingness (Bowles \& Gintis, 1976, op. cit.in Kyritsis, 2016: 92).

Interestingly, with this view, are aligned many scholars and modern philosophers who express their doubts about whether or not, school manages to fulfil its mission in terms of reducing social inequalities and offering to all students the same opportunities for development and social inclusion. Thus, Bernstein (1977) supports that, education as an institution is never neutral and contributes to the reproduction and legitimization of social hierarchy, by promoting standards which are similar to power relations in society and, by acting as a catalyst in student's formation of values and predispositions; whereas, Bowles (1972) focuses on teachers' low expectations from the non-favored students, pointing out that according to them, these students will have low academic performance, will graduate early and will pursuit a profession similar to that of their parents. Furthermore, Bourdieu (1977), through the notion of habitus, emphasizes the importance of education in shaping habits and the responsibility of educational organizations in order to face social inequalities. ${ }^{1}$ Finally, from his part, Chomsky (2000) notes that, in the name of democracy, schools perpetuate the myth that we live in a classless society, "miseducate" students, they proselytize them in a thinking culture in favor of serving powerful persons' interests, which, in case they do not adopt, they will be marginalized by the system (Chomsky, 2000; op. cit. in Kyritsis, 2016: 96-97).

\section{Proposition 1: Educational institutions appear to be rather inadequate to fulfill their mission and meet emerging social requirements}

Nowadays, many social groups of our society appear to be systematically blocked from basic rights, opportunities and various spheres of activity which are fundamental to social integration. In its broaden definition, the term "social exclusion" is connected with poverty and unemployment (Levitas, 1996; Paugam, 1993), with the process of long term non-participation in the economic, social and political life and norms and; may be considered as an obstacle for social integration (Burchardt, Le Grand, \& Piachaud, D., 1998).

Evidence suggests that, exclusionary forms of discrimination may be seen within educational communities and may be connected with students' professional future and their adult life chances as long as a significant number of young people leave school without attaining qualifications or basic and personal skills. To be more specific, whilst research on employability (Kleinman, West \& Sparkes, 1998; Moss and Tiley, 1995) emphasizes the importance of individuals' personal qualities and soft skills in accessing the labor market; Sparkes (1999) argues that, combinations of social disadvantage powerfully affect school performance as well as early adult outcomes.

From the above, we can conclude that, educational institutions as well as the practices they adopt should change so as to create a substantially just society (Giroux, 1988); should give equal access to culture for all through the effective teacher-student cooperation and, should invest on the production of substantial learning outcomes, the cultivation of moral values, as well as, on the complete redesign and redefinition not only of the curriculum, practices and methods, but also, of philosophy and mission. At this point, we underline educational leadership's responsibility in mitigating inequalities and promoting just standards.

\section{Educational leadership: trends and suggestions for leading just schools}

Interestingly, the theme of educational leadership invites a wide-ranging spectrum of theoretical perspectives, methods, and applications, both classic and contemporary, which investigate leadership's processes and outcomes.

\footnotetext{
${ }^{1}$ Bourdieu (1977) identifies habitus as all the predispositions by which one can learn, from an early age, to act in social interactions. These habits are unconsciously shaped by past and current experiences and, seem to reflect the social conditions under which they were acquired. Therefore, habitus must be seen as the product of the interactions, habits and predispositions of the individual with the environment in which his action is registered.
} 
Educational leaders are called to face various challenges as well as constant changes of organizational environment, to create a vision, to set new goals and, to inspire, motivate and encourage the other members of school community to achieve them, while, effective leadership appears to be a critical factor for organizational sustainability and growth (Bourantas, 2005, Vacola \& Nicolaou, 2012).

Furthermore, many scholars suggest that, leadership is connected with school effectiveness (Marzano, Waters, and McNulty, 2005) and, more precisely, leadership has a direct effect on school organization, school ethos, teacher efficacy, staff morale and satisfaction, staff retention, teachers' commitment, teachers' extra effort and, students' achievements (Ashton \& Webb, 1986; Geijsel, Sleegers, Leithwood, \& Jantzi, 2000). Interestingly, the coding of leadership behavior has been the subject of many researches who reveal the necessity of constructing new models and more sophisticated conceptual frameworks for leadership reflecting current needs and demands (Fullan, 2006; Quinn, 1996, Walker and Quong, 2010). Respectively, various categorizations and typologies have been developed regarding school leadership, such as the democraticauthoritarian-enabling model, the transactional model (Hoy \& Miskel, 2008), the transformational model (Bass, 1985), the authentic model (Luthans \& Avolio 2003), etc., emphasizing that, although instructional and pedagogical knowledge are necessary for an effective school leader, technical skills are not sufficient.

Thus, much of the current literature on educational leadership underlines the necessity for active engagement of all stakeholders in everyday school life and, for a more democratic leadership style (Shields, 2010; Shields, 2004; Senge, 1990; Sergiovanni, 2001), which is completely different from the traditional hierarchical, bureaucratic and autocratic style and, which would encourage teachers' and students' active participation in decision making and, would foster organizational meaningfulness, interconnecting school with complex society's demands.

Given that, according to Biesta (2009), we have to emphasize the importance of the democratic quality of the processes and practices that make up the everyday lives of children, young people and adults for their ongoing formation as democratic citizens, we can assume that, whilst researchers did argue for the distinctiveness of their terminology, the terms which determine and point out certain leadership styles, could be well-linked with democratic leadership as well (Hwa, 2008).

\section{Proposition 2: Educational leaders should invest on social justice}

Undoubtedly, educational community's fundamental aim is to enable students to gain knowledge and skills for socio-professional development and completion. Thus, we can assume that school leaders must have also skills so as to lead socially just schools. At this point, social justice scholarship in educational leadership emphasizes moral values, justice, respect, care, and equity (Cambron-McCabe and McCarthy, 2005) and reveals the necessity of fundamental rethinking of school's agenda so that students gain knowledge and engage in critical reflection. Expanding these assumptions, we can assume that, school leaders need to embody a social justice consciousness within their belief systems or values (...) and need to know about evidence-based practices that can create an equitable school (Capper, Theoharis, Sebastian, 2006).

Undeniably, the interest for the concept of social justice has deep roots in the philosophical thinking of our society. Since the ancient times, there is vivid interest and concern for justice and its linkage to education, equity and recognition among the members of a democratic society. Philosophers such as Plato and Aristo$\mathrm{tle}^{2}$, support that society (the total) precedes the individual (the part) and, all individual effort should serve the common good. In modern times as well as in the late 19th century-early 20th century, the relationship between society and education is the subject of study of pedagogues and researchers (Comenius; Rousseau; Dewey 1916; Durkheim, 1966, etc.). Social justice refers to the organization of the complexity of modern pluralistic society in order to provide to all citizens and to ensure the conditions for a meaningful life and harmonious coexistence. To be more specific, it means that, rights and obligations are distributed in a rational manner; expanded possibilities of self-realization are given to all; emphasis is put on the significance and value of voluntary participation in the implementation of a collective project; democratic procedures are guaranteed by equal participation of all (social); groups; respect and understanding are promoted.

Given the aforementioned discussions of the concept, we can understand the importance and the crucial role of social justice in the formation of equal and active citizens who respect each other and, whose action is

\footnotetext{
${ }^{2}$ More specific, Aristotle considers justice as a habit (“exis") and as one of the most important moral virtues connected with the moral commitment; since, a citizen by acting well, through the expression of his rights and obligations; seems to promote social well-being and bliss.
} 
pointing to the collective good. Thus, into this array of competing demands and pressing challenges comes another compelling claim: educational leaders are expected to be transformative, to attend to social justice as well as academic achievement and create inclusive and socially just learning environments (Shields, 2004; Shields, 2010).

Within the organizational context, fostering social justice and social inclusion implies to change the nature of relationships among actors involved and to strengthen organizational culture, goals, values and beliefs (Pratt, 2000) by enriching membership and tasks according to our complex society's needs. Much of the current literature on school leadership suggests that, within democratic schools where leaders share responsibilities, teachers are more likely to actively participate in policy planning and decision-making (Sutton \& Wheatley, 2003, Day 1998; Hammersley-Fletcher \& Brundrett, 2005); feel empowered and, appear to consider their development in a positive way (Sergiovanni \& Starratt, 1998). Moreover, educational leaders who foster social justice and democratic practices seem to be more productive; undertake adequate initiatives and adopt distributed leadership models (Gronn, 2003); share their expertise with positive effects on the whole school functioning (Hammersley-Fletcher \& Brundrett, 2005); and can handle properly the relationship of transformative leadership and deep and meaningful school change (Shields, 2010).

Leadership for social justice therefore, is another approach to leadership which questions not the relationship between leadership and effectiveness but the way schools should approach effectiveness in times of crisis (Koutouzis, 1999). Moreover, since active participation in social and professional life is an indicator of the quality of life (Hofstede, 2001; Wernick, Kulick, A. \& Inglehart, 2013), we assume that educational organizations should foster active engagement and transform students' civic attitude and frames of reference. Towards this direction, activities enhancing students' social skills and curricula regarding civic and citizenship education seem to help students develop socio-affective and cognitive aspects of their personality so that they face successfully challenges such as bullying, discriminations while, it gives them voice to participate actively and contribute positively in their school, community and society. In our point of view, educational and therefore, social exclusion is not accepted as a "normal" side effect in search for excellence and increased measurable educational outcomes. They are rather considered as non-rational, problematic situations which school leaders should focus on (Koutouzis, 1999).

Thus, educational leaders have the responsibility to create the conditions under which school could play a formative role in linking the new multicultural citizenship education, balancing unity with diversity (Banks, 2001) and, contributing to the defense and the maintenance of universal values of human rights and fundamental freedoms.

\section{Implementing social justice and democratic practices}

\subsection{Building the bridges}

Leader's responsibility of de-constructing organizational context (practices, processes, mission and goals) so as to implement and maintain a new more democratic "philosophy" appears to be a challenging emergence of our times. With the view to achieve its mission, modern school should completely revise its philosophy and practices, by opening the dialogue with all stakeholders (principals, teachers, students, parents, academics, local community and NGOs) and by reconsidering the objectives and practices in order to be less meaningless for its participants. Evidence suggests that democratic citizenship is not simply an existing identity that individuals just need to adopt, but is an ongoing process that is fundamentally open towards the future (Biesta, 2011).

Thus, educational leaders have to face with tremendous pressure, they are expected to develop learning communities, build the professional capacity of teachers, take advice from parents, engage in collaborative and consultative decision making, resolve conflicts, engage in effective instructional leadership, and attend respectfully, immediately, and appropriately to the needs and requests of families with diverse cultural, ethnic, and socio-economic backgrounds (Shields, 2004). Therefore, we argue that the emphasis on social justice could be a key which, educational leaders have to cultivate and invest on it by strengthening organizational culture, fostering cooperative practices and processes, enriching curricula and cultural activities, facing with respect diversity and other challenging social issues and, finally, opening a moral dialogue with all actors involved.

Interestingly, a meta-analysis of research on school leadership found that principals' responsibilities most strongly associated with higher student achievement include "culture" "situational awareness"; and "input" (Marzano, Waters, \& McNulty, 2005: 42-43). 
On the basis of the aforementioned literature, we further build our theoretical model (see Figure 1) and we argue that, leader's skills and concern for social justice and social inclusion offer unique opportunities to educational communities for promoting curricula, behaviors and organizational processes which are socially-embedded and which reveal the new dynamic and positive role that school has to play within modern societies.

Proposition 3: educational leaders can invest on a strong organizational culture that fosters just practices and core values.

Proposition 4: educational leaders have to develop situational awareness, emphasizing on learning organization and school's open dialogue with society.

Proposition 5: educational leaders can assure equal opportunities for all students, through educational activities and roles' division, against educational homogenization which pre-defines students' future.

\subsection{Strong organizational culture}

Indisputably, leaders' capacity to create a strong and transparent organizational culture reflecting and fostering a commitment to integrity and social values would improve the whole organization's performance and internal cohesion and, would inspire all actors involved. Shields (2004) underlines that, current practices and beliefs may be challenged and changed through transformative leadership, strong relationships, and moral dialogue.

It is obvious that, when individuals are treated with dignity, respect and value for their contributions, and not simply as the occupant of a role, they are likely to obtain a sense of meaningfulness from their interactions (Locke \& Taylor, 1990; Guerra \& Pazey, 2016). Educational leaders' success, job satisfaction, and willingness to see the job through appear to hinge on their people skills and, enable them to create a cohesive school culture based on cooperation and trust. It is obvious that, cooperation as well as cooperative behaviors are one of the most important social and political stakes of modern societies of information and knowledge (Sakalaki, 2010).

Given that leadership style, organisational culture and, organisational justice (Cameron \& Quinn 2005; Cropanzano et al 2001) can influence and shape employee's perception of their work tasks, goals and relations, we argue that building and maintaining a strong and open organizational culture based on collectively set core values, will enhance organization's democratic orientation and will put school in a dialectical relationship with the environment. Covey (2001), suggests that principle- centred leadership may be the ethical compass which leads to organizational success. Hence, educational leaders should create a strong system of core values which will act as a catalyst of change and will mobilize all stakeholders.

\subsection{Situational awareness}

The term of awareness is connected with one's authenticity, systems thinking as well as one's capacity to recognize one's inner standards, values, emotions, strengths and weaknesses, whereas, in a broadened sense, social awareness seems to be a top criterion which leads to organizational overall success and, which requires one's empathy, respect, diplomacy and determination so as to provide high quality results (Goleman, Boyatzis \& McKee, 2014; Jacobs, 2001). According to them, genuine leaders have the responsibility to capture people's passion, rejuvenate their interest and connect them with the vision of what they could be, through the approach of dynamic inquiry which activates people to "paint a painting of organizational soul" (McKee, A \& McMillen, C., 1992).

Consequently, educational leaders for social justice have to transcend their typical role and put the bases for cooperation, trust, and respect by encouraging learning and training as well as the construction of networks, both internally and externally. This investment on personal and organizational development permits organizations to improve their quality of services, to act pro-actively in a rapidly changed environment and, finally to create their own future (Berila, 2016; Senge, 1990).

Therefore, we assume that situational awareness may help educational leaders to transform educational organization into a learning organization and gives the opportunity to all actors involved to continually acquaint knowledge connected with organizational goals and targets by creating a safe context of open dialogue, experimentation and innovation. Moreover, situational awareness may help organizations to maintain collective targets through interactions; to re-consider points of view and ideas as well as to face problems successfully. Thus, this concept is a key element in organizational success and, may be seen as an opportuni- 
ty for modern organizations in order to be engaged in a well-designed multifaceted process which spans individuals, groups and organizational culture, activates changes and, empowers organizational sustainability as well as organizational capacity of adjustment in a changing environment.

Hence, we posit that, educational leaders with situational awareness should emphasize on transforming school into a learning organization, facilitating the development of its members; strengthening their skills, competencies and abilities and, thus, permitting school's linkage to the emerging society's demands.

\subsection{Curricula: the necessity for citizenship education and social inclusion in a global world}

It is true that, the last decades have witnessed a continuing decline in formerly coherent value systems and an increasing individualization in modern west society. Moreover, the tendency towards globalization has broadened the cultural spectrum in which many people live and society has become more diverse.

In today's globalized and interconnected world, living together peacefully has become a moral, social and political imperative and, education -in its widest sense- is called upon to play a major role in this worldwide shared task. Nowadays, fostering and developing active citizenship ${ }^{3}$ and democratic participation is put forward as a solution for a multidimensional crisis (political, cultural, social and economic) (Karakatsani \& Papaloi, in press).

The recent discussions of citizenship assert the importance of balancing rights and responsibilities whereas, in the recent discourse of citizenship education, the term 'active citizenship' can be understood as referring not only to the nature of citizenship, but also to a process of experiential learning. Therefore, teaching citizenship comprises the affective level (development of intercultural understanding), the cognitive level (acquisition of operational competence) as well as the pragmatic level (acquisition of knowledge and skills through practice and experience) (Hoskins \& Crick, 2010). It may be broadly stated that, education for citizenship appears to be very significant for students' future social and civic involvement and well-being, since, passive people who are not involved in any type of social activity appear to have the lowest level of life satisfaction and often feel alienated.

Although curricula require that students be taught the skills of responsible action and participation, minimal explicit conceptual or methodological guidance is usually provided. Moreover, whilst, citizenship education should enable (...) students to acquire the knowledge, attitudes, and skills needed to act to make (...) the world more democratic and just (Banks, 2004); current civic learning is primarily characterized by procedural knowledge and compliant codes of behavior that do not envelope students in collective action for systematic understanding of social and political issues.

Thus, today's school reform agenda requires leadership models, curricula and initiatives orientated towards more participative and democratic processes which enhance both students' learning and their social engagement (Hwa, 2008), taking into consideration, at the same time, students' everyday life experiences.

Undeniably, democratic societies need active, responsible and informed citizens who are able and willing to contribute responsibly to political procedures by knowing their rights and obligations (Perlman et al., 2015). Aristotle argues that citizens possess limits and virtues that are accepted by society whereas; good persons have moral values. Thus, bliss and well-being are connected with our actions and must be the result of logical thinking, education and habits. According to this philosopher, only through participation in public affairs human beings will be able to "meet" the power and "hear" the voice that is hidden inside them.

Thus, civic and moral education should invest, on the one hand, on developing a rational citizen (Habermas, 1993) through the construction of civic identity/ responsibility/ engagement, participation, political consciousness, tolerance and acceptance of the other, on the other hand, on enhancing social cohesion and integration as well as students' socio-cognitive development through "critical consciousness" (Freire, 1973). Towards this direction, many scholars underline the importance of participatory and engaged learning for democracy and social justice (Nagda, Gurin, \& Lopez, 2003) as well as active and experiential learning (Kolb, 1984); demonstrate the need for reconstruction of the whole educational process and, put the emphasis on educational community's connection with society, by encouraging students to deeply explore social context, its mechanisms and regulations. On the other hand, we have also to re-think about democratic

\footnotetext{
${ }^{3}$ The following indicators for active citizenship, assumed to be a competency-based activity, are listed: voluntary work, political participation, interests groups and public debate. Based on these indicators, we make a distinction between input and output indicators. Output indicators (for example, political and civic knowledge, political efficiency, etc.) refer to what has been learned, while input indicators refer to the learning process itself (content of education and culture in education).
} 
teachers' efficacy and learning models for democracy (Andrews et al., 2017; Holden \& Kitchen, 2016; Wheatley, 2005; Wernick, Kulick \& Inglehart, 2013). Thus, despite the plethora of initiatives so as to revitalize democracy, educational organizations will be unable to foster citizenship if they do not de-construct school reality and they do not pay attention on crucial issues regarding teachers' as well as students' substantial engagement.

\section{Meta-leadership priorities: maintaining "democracy"}

Covey (2001) argues that we cannot transform a swamp into an environment where total quality blossoms, without having inculcating firstly, fundamental habits and core values. It is true that, it is very difficult to introduce and maintain changes, especially in bureaucratic organizations where rigid structures and systems, routine as well as competiveness have led employees to professional fossilization. Undeniably, in every organization, there exist powers of harmony and powers of disharmony affecting organizational culture and organizational intelligence (Goleman, Boyatzis \& McKee, 2014) that should be taken into consideration.

The investment on social justice and social inclusion should be seen as a strategic challenge and as a cornerstone in leadership practice which contributes to organizational transformation. Consequently, educational leadership's meta-priority should be, on the one hand, the inculcation of a sense of security to all actors involved, on the other hand, the investment on initiatives encouraging innovation and linkage with society's emerging needs. Moreover, a new model of democratic teacher's efficacy must be proposed (Wheatley, 2005), conceptualizing priorities and learning needs. Of course, the idea of widespread participation in school affairs as a feature of democratic schools is thus not as simple as inviting participation, because the right to "have a say" introduces questions about how various viewpoints fit into the fragile equation balancing special interests and the larger "common good" of the democratic community (Apple \& Beane, 1989). Nevertheless, this would inspire, deliberate and empower them to act freely upon collectively preset core values and vision and, at the same time, would reduce resisting powers (Covey, 2001), by creating some kind of powerful coordination and mutual dialogue. Concluding, according to the aforementioned literature, organizational culture, educational activities and curricula as well as development learning process may create a safe context on which educational leaders have to invest.

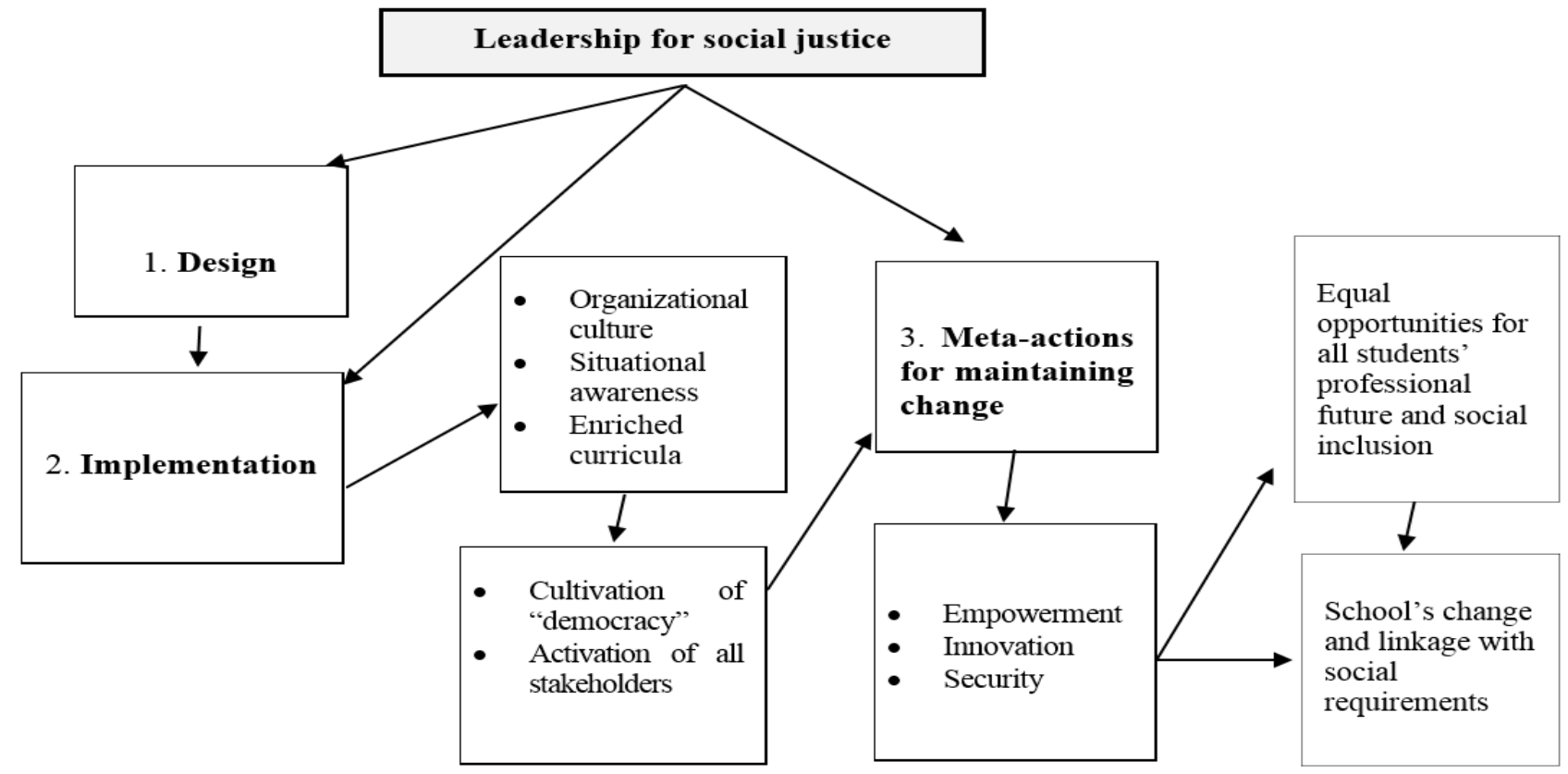

Figure 1. Leadership for social justice

\section{Conclusions}

In recent years, many scholars have revealed the importance of educational leadership for social justice for organizational sustainability and growth in micro-, macro- and meta-level. Interestingly, emphasis has been given, in the last decades, on the question of citizenship, the elimination of social exclusion as well as the formation of democratic dispositions and allegiances. The focus in establishing "democracy" within educational organizations has been often fueled by concerns about decreasing levels of civic participation and political involvement, and by wider concerns about social cohesion and inclusion. 
The aim of the present paper is to offer additional insights on social justice and the way it is connected and contributes to an effective educational leadership which reflects and proactively meets society's complexity.

Based on the recent literature and trends, we tried to define the framework for an effective educational leadership and organizational growth putting the emphasis on practices, mechanics, strategic behaviour, leadership, ethics, and curricula that reflect modern democratic school's values, mission and vision. It is our proposition that, educational leadership for social justice, would act proactively for the common good of all actors involved and, would be an investment for organizational growth and, thus, societal prosperity. Our attempt closely follows the literature on the basic concepts which were discussed in this paper, with a view to increase clarity and reduce ambiguity as to social justice, active citizenship and social inclusion necessity and applicability in the area of educational leadership. Through this brief analysis of school's reality, we tried to highlight the importance of these concepts and, to relate them with leadership strategic choices and organizational processes (culture and situational awareness) as well as curricula. Interestingly, the most powerful meaning of democracy is formed not in glossy political rhetoric, but in the details of everyday lives (Apple \& Beane, 1989). We propose to defend the idea of a leadership orientating towards the emerging social needs which would reflect ethical and moral values that are critical for school's sustainability and evolution. We assume that, this educational leadership model whose core values are commitment to learning, commitment to educational community's empowerment could promote the social, emotional and professional development of all actors involved (school principal, teachers, and students) by helping them become independent, autonomous, mature, critical thinkers and, thus, active citizens. Moreover, we posit that modern curricula and activities have to be enriched and foster more participative and democratic processes, taking into account current social needs for active citizenship and social inclusion. Indisputably, the above assumptions constitute for leaders a strategic challenge which fosters organizational growth and sustainability. Nevertheless, we have to admit that education is not the ultimate lever for social transformation, but without it transformation cannot occur (Freire, 1998: 37).

With this paper, we have introduced a leadership model, whereby social justice and democratic processes can contribute to school's effectiveness, sustainability and growth. Nevertheless, this paper is not without limitations, nor does it provide a complete understanding of how these aspects of educational leadership for social justice may help educational leaders to create a strong organizational culture and lead their school and students to the success. In this direction, further analysis of the determinants of social justice and their connection with leadership practices in the meso- and macro-level of school's functioning will be helpful.

\section{References}

1. Andrews, D.J., Carter, R., Gail S. D. (2017). Teacher Education and Teaching in the present political landscape:promoting educational equity through criticalinquiry and research. Journal of Teacher Education, 68(2).

2. Apple, M. \& Beane, J. (1989). Lessons from Democratic Schools. Irish Educational Studies.

3. Ashton, P. T., \& Webb, R. B. (1986). Making a difference: Teachers' sense of efficacy and student achievement. White Plains, NY: Longman.

4. Banks, J. (2004). Diversity and Citizenship Education, Global Perspectives. John Wiley \& Sons.

5. Banks, J. (2001). Cultural diversity and education: Foundations, curriculum, and teaching, 4th ed. Boston: Allyn and Bacon.

6. Bass, B. M. (1985). Leadership and performance beyond expectation. New York: Free Press.

7. Berila, B. (2016). Integrating Mindfulness into Anti-oppression Pedagogy: Social Justice in Higher Education, NY: Routledge.

8. Bernstein, B. (1977). Social class, language and socialization. In J. Karabel \& A.H. Halsey (Eds), Power and ideology in education. New York: Oxford University Press.

9. Biesta, G. (2011). Learning democracy in school and society. Education, lifelong learning and the politics of citizenship. Rotterdam: Sense Publishers.

10. Biesta, G. (2009). What Kind of Citizenship for European Higher Education? Beyond the Competent Active Citizen. European Educational Research Journal, 8(2), 146-158.

11. Bourantas, D. (2005). Leadership, the way of constant success. Athens: Kritiki.

12. Bourdieu, P. (1977). Cultural reproduction and social reproduction. In J. Karabel \& A.H. Halsey (Eds), Power and ideology in education. New York: Oxford University Press. 
13. Bowles, S. (1972). Unequal education and the reproduction of the social division of labor. In R. Dale, G. Esland \& M. MacDonald (Eds), Schooling and capitalism. A sociological reader. London: Routledge \& Kegan Paul.

14. Burchardt, T., Le Grand, J. and Piachaud, D. (1998). Social Exclusion in Britain 1991-1995. Social Policy and Administration, 33(3), 227-244.

15. Cambron-McCabe, N., McCarthy, M. (2005). Educating school leaders for social justice. Educational Policy, 19(1), 201-222.

16. Capper, C., Theoharis, G., Sebastian, J. (2006). Towards a framework for preparing leaders for social justice. Journal of Education Administration, 44(3), 209-224.

17. Chomsky, N. (2000). Chomsky on miseducation. Edited with an introduction by D. Macedo. Lanham, Maryland: Roman \& Littlefield.

18. Chomsky, N. (1987). On power and ideology. Boston: South End Press.

19. Covey, S. (2001). Principle centred leadership. Athens: Kleidarithmos.

20. Cropanzano, R., Byrne, Z. S., Bobocel, D. R., and Rupp, D. R. (2001). Moral virtues, fairness heuristics, social entities, and other denizens of organizational justice. Journal of Vocational Behavior, 58, 164209.

21. Dewey, J. (1916, 1980). The need for social psychology. In J. A. Boydston (Ed.). John Dewey: The middle works, 1899-1924, 10, 53-63. Carbondale, IL,,: Southern Illinois University.

22. Durkheim, E. (1966). Education et sociologie. Paris: PUF.

23. Day, C. (1998). Working with the different selves of teachers: beyond comfortable collaboration. Educational Action Research, 6(2), 255-275.

24. Freire, P. (1977). Education of the oppressed. Athens: Kedros-Rappa.

25. Freire, P. (1998). Pedagogy of freedom: Ethics, democracy, and civic courage. Lanham, MD: Rowman \& Littlefield.

26. Fullan, M. (2006). Leadership \& Sustainability, Systems Thinkers in Action. Thousand Oaks, CA: Sage Publications.

27. Geijsel, F., Sleegers, P., Leithwood, K., \& Jantzi, D. (2003). Transformational leadership effects on teachers' commitment and effort toward school reform. Journal of Educational Administration, 41(3), 228-256.

28. Giroux, H. (1988). Teachers as intellectuals: Towards a critical pedagogy of learning. South Hadley, MA: Bergin and Garvey.

29. Goleman, D., Boyatzis, R., Mckee, A. (2014). Primal leadership. Athens: Pedio.

30. Gronn, P. (2003). Leadership: Who needs it?. School Leadership \& Management, 23(3), 267-291.

31. Guerra, P.L., Pazey, B.L. (2016). Transforming Educational Leadership preparation: starting with ourselves. The Qualitative Report, 21(10), 1751-1784.

32. Hammersley-Fletcher, L. \& Brundrett, M. (2005). Leaders on leadership: the impressions of primary school head teachers and subject leaders. School Leadership \& Management, 25(1), 59-75.

33. Hofstede, G. (2001). Culture's consequences: Comparing values, behaviors, institutions, and organizations across nations (2nd ed.). Thousand Oaks, CA: Sage.

34. Holden, M., Kitchen, J. (2016). Evolving practices: Admission policies in Ontario Teacher Education Programs. Canadian Journal of Education, 39(4).

35. Hoskins, B.; Crick, R. D. (2010). Competences for Learning to Learn and Active Citizenship: different currencies or two sides of the same coin? European Journal of Education. 45(1), Part II. Jochum V.

36. Hoy, W. K. \& Miskel, C. G. (2008). Educational administration: Theory, research, and practice, 8th edition. New York: McGraw-Hill.

37. Hubermas, J. (1993). The philosophical discourse of modernity. Twelve lectures. Athens: Alexandreia.

38. Hwa, C. L. (2008). The impact of principal's transformational democratic leadership style on teachers' job satisfaction and commitment. Thesis. Malaysia:Universiti Sains of Malaysia.

39. Jacobs, R. (2001). Using human resource functions to enhance emotional intelligence. In C. Cherniss and D. Goleman (Eds), The emotionally intelligent workplace: how to select for, measure and improve emotional intelligence in individuals, groups and organizations, San Francisco: Jossey-Bass.

40. Karakatsani, D., Papaloi, E. (in press). School learning architecture for active citizenship and social justice based on organisational meaningfulness. In Palaiologou, N. \& Zembylas, M. (Eds), Human rights and citizenship education, an intercultural \& international perspective. Cambridge: Cambridge Scholars.

41. Kleinman, M., West, A. and Sparkes, J. (1998). Investing in employability the role of business and government in the transition to work. London: BT/LSE. 
42. Kolb, D. (1984). Experiential learning: Experience as the source of learning and development, Ennglewood Cliffs, NJ: Prentice-Hall.

43. Koutouzis, M. (1999). Basic Principles of Management. Patra: Hellenic Open University.

44. Kyritsis, D. (2016). Educational inegalities and social justice. Athens: Gutenberg.

45. Levitas, R. (1996). The concept of social exclusion and the new Durkheimian hegemony, Critical Social Policy, 46, 5-20.

46. Leithwood, K. A., \& Jantzi, D. (2000). The effects of transformational leadership on organizational conditions and student engagement with school. Journal of Educational Administration, 38(2), 112-129.

47. Locke, E. A., and Taylor, M. S. (1990). Stress, coping, and the meaning of work. In A. Brief and W. R. Nord (Eds.). Meanings of occupational work (pp. 135-170). Lexington, MA: Lexington Books.

48. Luthans, F., \& Avolio, B. J. (2003). Authentic leadership development. In K. S. Cameron, J. E. Dutton, \& R. E. Quinn (Eds.), Positive organizational scholarship: 241-258. San Francisco: Berrett-Koehler.

49. Marzano, R., Waters, T., and McNulty, B. (2005). School leadership that works. Alexandria, VA: Association for Supervision and Curriculum Development.

50. Mckee, A. \& McMillen, C. (1992). Discovering social issues: organizational development in multicultural community. Journal of Applied behavioral Sciences, 28(3), 445-460.

51. Moss, P. and Tiley, C. (1995). Soft skills and Race: An investigation of black men's employment problems. New York: Sage Foundation.

52. Nagda, B., Gurin, P. \& Lopez, G. (2003). Transformtive pedagogy for democracy and social justice. Race Ethnicity And Education, 6/ 2.

53. Paugam, S. (1998). La dynamique de la disqualification sociale, Science Humaines.

54. Perlman, D., Hunter, A., Stewart, A. (2015). Psychology, History and Social Justice: Concluding Reflections. Journal of Social Issues, 71(2), 402-413.

55. Pratt, M. (2000). The good, the bad, and the ambivalent: Managing identification among Amway distributors. Administrative Science Quarterly. 45, 456-493.

56. Sakalaki, M. (2010). Autonomy, interiority, and quality of interpersonal relations as factors of cooperativity. In S. Papastamou, et al. (Eds.) Social thinking, cognition and behavior, pp.171-183.Athens: Pedio.

57. Shields, C. M. (2010). Transformative leadership: Working for equity in diverse contexts. Educational Administration Quarterly. 46(4), 558-589.

58. Senge, P. (1990). The fifth discipline: the art and practice of learning organization. New York: Doubleday.

59. Sergiovanni, T.J. (2001). Leadership: what's in it for schools? London: RoutledgeFalmer

60. Sergiovanni, T.J., Starratt R.J. (1998). Supervision: A Redefinition (6th Edn). New York: McGraw-Hill.

61. Shields, C. (2004). Dialogic Leadership for Social Justice: Overcoming Pathologies of Silence. Educational Administration Quarterly. 40(1), 109-132.

62. Sparkes, J. (1999). School, education and social exclusion. Centre for Analysis of Social Exclusion (CASE), London School of Economics, CASEpaper.

63. Sutton, R.E. \& Wheatley, K.F. (2003). Teachers' Emotions and Teaching: A Review of the Literature and Directions for Future Research.Educational Psychology Review, 15(4), 327-358.

64. Vakola, M, Nicolaou, I. (2012). Organizational psychology and behavior. Athens: Rossili.

65. Walker, A., Quong, T. (2010). Leading upstream: Professional learning for middle leaders. In Anthony H. Normore (ed.) Global Perspectives on Educational Leadership Reform: The Development and Preparation of Leaders of Learning and Learners of Leadership (Advances in Educational Administration, Volume 11) Emerald Group Publishing Limited, pp.357 - 376.

66. Wernick, L., Kulick, A., Inglehart, M. (2013). Factors predicting student intervention when witnessing anti-LGBTQ harassment: The influence of peers, teachers, and climate. Children and Youth Services Review, 35(2), 296-301.

67. Wheatley, K. (2005). The case for reconceptualizing teacher efficacy research. Teaching \& Teacher Education, 21(7), 747-766. 